\title{
Safety and feasibility of outpatient autologous stem cell transplantation in pediatric patients with primary central nervous system tumors
}

\author{
Jane Koo ${ }^{1} \cdot$ Stacy Silverman ${ }^{1} \cdot$ Brandon Nuechterlein $^{1} \cdot$ Amy K. Keating ${ }^{1} \cdot$ Michael R. Verneris ${ }^{1} \cdot$ \\ Nicholas K. Foreman ${ }^{1,2} \cdot$ Jean M. Mulcahy Levy ${ }^{1,2}$
}

Received: 7 December 2018 / Revised: 28 January 2019 / Accepted: 1 February 2019 / Published online: 19 February 2019

(c) The Author(s) 2019. This article is published with open access

\begin{abstract}
High-dose chemotherapy with autologous hematopoietic stem cell transplantation (autoHSCT) is a well-established treatment for pediatric central nervous system (CNS) tumors. Given the risks of toxicity and infection, pediatric autoHSCT has been historically performed on hospitalized children. As our practice evolved, some patients were transplanted as outpatients. We performed a retrospective cohort analysis of 37 patients who received 90 transplant procedures (49 outpatient and 41 inpatient) at Children's Hospital Colorado. The most common primary diagnosis was medulloblastoma $(51.4 \%)$. Of the patients transplanted as outpatients, $69.4 \%$ were admitted for fever and neutropenia and had a median time to hospitalization of day +6 , with fever and neutropenia being the most common reasons for admission. The median time to neutrophil engraftment was the same in both cohorts, 11 days. Median time to platelet engraftment was 13 days (8-82 days) vs 16 days $(8-106$ days $)(p=0.0008)$. At day +100 , the transplant-related mortality (TRM) was $0 \%$ for both the cohorts. At a median follow-up of 1.7 years, overall survival (OS) for all patients was $66.1 \%$ and TRM was $0 \%$ for both the cohorts. Outpatient autoHSCT for properly selected children with CNS tumors is safe and effective.
\end{abstract}

\section{Introduction}

High-dose chemotherapy with autologous hematopoietic stem cell transplantation (autoHSCT) is a well-established treatment for multiple types of pediatric central nervous system (CNS) tumors [1-13]. Bacterial infections continue to be a major cause of morbidity and mortality in pediatric patients undergoing high-dose chemotherapy and autoHSCT. The incidence of bacteremia prior to engraftment in all types of pediatric transplant recipients is considerable and still accounts for significant morbidity and mortality. Previously, the incidence of bacteremia, specifically in pediatric autoHSCTs, has been reported to range

Jane Koo

jane.koo@childrenscolorado.org

1 Department of Pediatric Hematology/Oncology/Bone Marrow Transplant, University of Colorado, Children's Hospital Colorado, Aurora, CO, USA

2 The Morgan Adams Foundation Pediatric Brain Tumor Research Program, Children's Hospital Colorado, Aurora, CO, USA from 24 to $34 \%[14,15]$. More recently, in the era of antibiotic prophylaxis, the incidence of bacteremia for autoHSCT patients is reported to range from 7 to $15 \%$ [1618]. Information on infectious complications in pediatric CNS tumor patients treated with autoHSCT is quite limited, with only one dedicated study analyzing infections in this population, published in 2013, showing that catheter-related gram-negative bacteremia was the most common infectious complication [19].

Previously, autoHSCT has been strictly performed in the inpatient setting given the concerns for transplantassociated toxicity and infection. The safety and feasibility of outpatient autoHSCT for pediatric CNS tumor patients have not been considered. In adults, outpatient autoHSCT is routinely used in patients with multiple myeloma and lymphoma and has resulted in excellent outcomes [20-26]. However, performing outpatient transplantation in young children presents unique challenges, including an inability to articulate their clinical status and their well-recognized clinical deterioration in the setting of sepsis relative to adolescents and adults. To date, no study has analyzed the outcomes and infectious complications of pediatric CNS tumor patients receiving autoHSCTs in the 
outpatient setting. Due to the lack of evidence in the literature, we retrospectively compared the safety and efficacy of autoHSCTs in the outpatient setting for pediatric CNS tumor patients.

\section{Methods}

\section{Patients}

We performed a retrospective cohort study in all the pediatric patients with primary CNS tumors who received an autologous stem cell transplant between January 2011 and July 2017 at the Center for Cancer and Blood Disorders (CCBD) at Children's Hospital Colorado. All data were extracted from the electronic medical record. The decision to analyze patients starting from 2011 was due to the establishment of the electronic medical record allowing for the standardized evaluation of patient records. Transplant episodes were categorized as inpatient if the stem cell infusion occurred while admitted to the hospital and outpatient if both the conditioning regimen and stem cell infusion occurred in the outpatient infusion center. Patients provided written informed consent for the procedure. This study was approved by the Institutional Review Board at the University of Colorado (IRB 050149).

\section{AutoHSCT procedure in the outpatient setting}

Patients undergoing autoHSCT in the outpatient setting received all the care in the outpatient clinic within Children's Hospital Colorado. According to our internal algorithms, patients with stable medical conditions, a Karnofsky/Lansky Performance Status (KPS/LPS) score of $>60$, were expected to have manageable gastrointestinal toxicities from the preparative regimen, the primary caregiver was assessed to be willing to provide outpatient therapy, and were within a reach of $60 \mathrm{~min}$ from the hospital. For patients who did not require admission to the hospital, outpatient follow-up visits occurred at least three times a week or more frequently as needed.

\section{Conditioning regimens}

All patients received the standard chemotherapy regimen as delineated by the protocol determined by their primary diagnosis. The myeloablative chemotherapy dosing regimen for pediatric malignant brain tumors was carboplatin $17 \mathrm{mg} /$ $\mathrm{kg} /$ day and thiotepa $10 \mathrm{mg} / \mathrm{kg} /$ day on days 1 and 2 with peripheral blood stem cell infusion on day 4 of each cycle or $48 \mathrm{~h}$ after the last thiotepa dose [27].

\section{Stem cell mobilization, collection, and infusion}

Mobilization and collection of hematopoietic stem cells was performed based on established institutional protocols and guidelines. A minimum of $2 \times 10^{6} \mathrm{CD} 34^{+} / \mathrm{kg}$ stem cells were administered for each autologous transplant with a maximum of $5 \times 10^{6} \mathrm{CD} 34^{+} / \mathrm{kg}$ stem cells.

\section{Infection prophylaxis and treatment}

Patients undergoing inpatient autoHSCT received acyclovir and fluconazole for anti-viral and anti-fungal prophylaxis beginning from day +1 . Acyclovir and fluconazole were discontinued at the time of discharge. The outpatient cohort did not receive acyclovir or fluconazole prophylaxis. In the inpatient setting, bacterial prophylaxis was intravenous (IV) meropenem or cefepime starting when the Absolute Neutrophil Count (ANC) was $<500 / \mathrm{mm}^{3}$ or with the development of fever. For Pneumocystis jiroveci pneumonia (PJP) prophylaxis, IV pentamidine was started on day +25 and administered every 3 weeks. Prophylactic pentamidine was discontinued when the absolute lymphocyte count was greater than $1000 / \mathrm{mm}^{3}$.

\section{Other supportive care}

All the inpatients received granulocyte colony-stimulating factor (G-CSF) at $5 \mathrm{mcg} / \mathrm{kg} /$ dose every $24 \mathrm{~h}$ beginning on day +1 and continued daily until the ANC was greater than $2500 / \mathrm{mm}^{3}$ for 3 consecutive days. For outpatient transplants, all patients received pegfilgrastim (Neulasta) dosed appropriately for their weight on day +1 . With regard to transfusions, packed red blood cells were administered for a hemoglobin count of less than $8.5 \mathrm{~g} / \mathrm{dL}$. Platelet transfusions were administered for a platelet count of less than $20,000 / \mathrm{mm}^{3}$ or symptomatic bleeding. Scheduled and asneeded antiemetics were administered for patients actively receiving chemotherapy and to help control symptoms of nausea and vomiting. IV fluids were administered with chemotherapy as outlined in the protocol.

\section{Study endpoints}

Each transplant episode was treated as a separate encounter and classified as outpatient or inpatient. For each episode, the day from infusion on which the patient was admitted was documented. Duration of hospitalization, antibiotics initiated, the total number of days of antibiotic use, the number of blood cultures drawn, and the details of any infection were tabulated, including the site and type of infection, and the number of days from stem cell infusion was documented. The number of days spent in the ICU was also recorded. 
Table 1 Patient and disease characteristics

\begin{tabular}{|c|c|}
\hline Characteristics & All patients \\
\hline Number of patients, $n$ & 37 \\
\hline \multicolumn{2}{|l|}{ Gender, $n(\%)$} \\
\hline Male & $22(59.5)$ \\
\hline Female & $15(40.5)$ \\
\hline \multicolumn{2}{|l|}{ Ethnicity, $n(\%)$} \\
\hline Caucasian/white & $29(78.4)$ \\
\hline Hispanic & $5(13.5)$ \\
\hline Non-Hispanic native American & $2(5.4)$ \\
\hline Mixed & $1(2.7)$ \\
\hline \multicolumn{2}{|l|}{ Location of primary tumor, $n(\%)$} \\
\hline Posterior fossa region & $21(56.8)$ \\
\hline Pineal region & $8(21.6)$ \\
\hline Frontal lobe & $1(2.7)$ \\
\hline Brainstem & $2(5.4)$ \\
\hline Diffuse & $3(8.1)$ \\
\hline Others & $2(5.4)$ \\
\hline \multicolumn{2}{|l|}{ Primary diagnosis, $n(\%)$} \\
\hline Medulloblastoma & $19(51.4)$ \\
\hline NGGCT & $3(8.1)$ \\
\hline Pinealblastoma & $1(2.7)$ \\
\hline PNET & $8(21.6)$ \\
\hline ATRT & $5(13.5)$ \\
\hline ETMR & $1(2.7)$ \\
\hline \multicolumn{2}{|l|}{ Preparative regimens, $n(\%)$} \\
\hline Carboplatin/thiotepa & $25(67.6)$ \\
\hline Vincristine/carboplatin/thiotepa & $5(13.5)$ \\
\hline Others & 7 (18.9) \\
\hline Age at diagnosis, years, median (range) & $2(0.6-21)$ \\
\hline Age at the time of autoHSCT, years, median (range) & $3(1-23)$ \\
\hline
\end{tabular}

Data presented are $n(\%)$, unless otherwise indicated

HSCT hematopoietic stem cell transplantation, NGGCT nongerminomatous germ cell tumor, PNET primitive neuroectodermal tumor, ATRT atypical teratoid/rhabdoid tumor, ETMR embryonal tumors with multilayered rosettes

\section{Engraftment}

Neutrophil engraftment was defined as the first day of an ANC above $500 / \mathrm{mm}^{3}$ for 3 consecutive days. Platelet engraftment was similarly defined as a platelet count greater than $20,000 / \mathrm{mm}^{3}$ for 7 consecutive days without requiring a transfusion.

\section{Infection}

An infectious disease event was defined as any bacterial, viral, or fungal infection that was confirmed by laboratory testing, radiographic imaging, or physical exam and that required antimicrobial treatment. A central line-associated blood stream infection (CLABSI) was defined according to the Center for Disease Control guidelines (recovery of a pathogen from a blood culture (a single blood culture for organisms not commonly present on the skin and two or more blood cultures for organisms commonly present on the skin) in a patient who had a central line at the time of infection or within a 48-h period before the development of infection). The infection could not be related to any other infection the patient might have and must not have been present or incubating when the patient was admitted to the facility [28].

\section{Statistical methods}

Quantitative variables were reported as absolute numbers and percentages and expressed by the median and standard deviation, if normally distributed, and by the mean if not. Comparisons between groups were made using $t$ test. Kaplan-Meier methods and log-rank tests were used to compare the overall survival, and neutrophil and platelet engraftment. Box and whisker plots and unpaired $t$ test with Welch's correction were created to compare the number of hospital and ICU days and the number of days of antibiotic use between the outpatient and inpatient cohorts. Mean and standard error of the mean were reported. All $p$ values were two sided and considered statistically significant if $<0.05$.

\section{Results}

\section{Patient characteristics}

A total of 37 pediatric patients who underwent autoHSCT for primary CNS tumors were analyzed. Patient and disease characteristics are shown in Table 1. The indications for transplantation for the entire cohort include medulloblastoma (54\%), primitive neuroectodermal tumor (PNET, $19 \%$ ), atypical teratoid/rhabdoid tumor (ATRT, 14\%), nongerminomatous germ cell tumor (NGGCT, 8\%), pineoblastoma (3\%), and embryonal tumor with multilayered rosettes (ETMR, 3\%). Among all the patients, the median age at diagnosis was 2 years (range $0.6-21$ years) and the median age at the time of transplant was 3 years (range 123 years). Preparative regimens for patients are also shown in Table 1.

\section{Characteristics of outpatient and inpatient transplant episodes}

Differences in characteristics of outpatient and inpatient transplant episodes are shown in Table 2. In total, 49 transplant episodes occurred in the outpatient setting and 41 episodes occurred in the inpatient setting. The median age at 
Table 2 Outpatient and inpatient transplant characteristics

\begin{tabular}{|c|c|c|c|}
\hline & $\begin{array}{l}\text { Outpatient } \\
\text { transplant } \\
\text { episodes } \\
(n=49)\end{array}$ & $\begin{array}{l}\text { Inpatient } \\
\text { transplant } \\
\text { episodes } \\
(n=41)\end{array}$ & $p$ Value \\
\hline $\begin{array}{l}\text { Median age at } \\
\text { transplant, years, } \\
\text { median (range) }\end{array}$ & $2(1-10)$ & $4(1-23)$ & 0.005 \\
\hline $\begin{array}{l}\text { Karnofsky/Lansky } \\
\text { Performance Status at } \\
\text { the time of transplant, } \\
\text { median (range) }\end{array}$ & $90(70-100)$ & $80(50-100)$ & 0.007 \\
\hline \multicolumn{4}{|c|}{ Disease status at the time of transplant, $n(\%)$} \\
\hline $\mathrm{CR}$ & $25(51)$ & $15(36.6)$ & \\
\hline NTR & $4(8.2)$ & $1(2.4)$ & 0.11 \\
\hline GCR & 0 & $17(41.5)$ & \\
\hline PR & $13(26.5)$ & $3(7.3)$ & \\
\hline MD & $1(2)$ & $1(2.4)$ & \\
\hline $\mathrm{SD}$ & $1(2)$ & $1(2.4)$ & \\
\hline Relapse & $2(4.1)$ & $2(4.9)$ & \\
\hline Refractory & $1(2)$ & $1(2.4)$ & \\
\hline MR & $2(4.1)$ & 0 & \\
\hline \multicolumn{4}{|c|}{ Reasons for inpatient autoHSCT, $n(\%)$} \\
\hline Family preference & - & $22(53.7)$ & \\
\hline Physician preference & & $6(14.6)$ & \\
\hline Fever & & $5(12.2)$ & \\
\hline $\begin{array}{l}\text { Complication from } \\
\text { initial transplant }\end{array}$ & & $3(7.3)$ & \\
\hline Infection & & $1(2.4)$ & \\
\hline Renal insufficiency & & $2(4.9)$ & \\
\hline Others & & $2(4.9)$ & \\
\hline
\end{tabular}

Data presented are $n(\%)$, unless otherwise indicated

$H S C T$ hematopoietic stem cell transplantation, $C R$ complete response, $N T R$ near total response, GCR good clinical response, $P R$ partial remission, $M D$ minimal disease, $S D$ stable disease, $M R$ minimal response

transplant for the outpatient cohort was 2 years (range 1-10) and 4 years for the inpatient cohort $(p=0.005)$. The median KPS/LPS score for outpatient transplant episodes was 90 (range 70-100) compared to 80 (range 50-100) for inpatient transplant episodes $(p=0.007)$. Disease status at the time of transplant is also shown in Table 2. For the outpatient cohort, complete response was the most common disease status at the time of transplant (25 outpatient transplant episodes, $51 \%$ ) compared to good clinical response as the most common disease status at the time of transplant for the inpatient cohort (17 inpatient transplant episodes, 41.5\%) $(p=0.11)$. All patients transplanted in the outpatient setting were discharged from the clinic after stem cell infusion. Of the 41 inpatient transplant episodes, the most common reason for admission was family preference $(53.7 \%)$ or physician preference $(14.6 \%)$. The remaining reasons for the transition to inpatient status are detailed in Table 2. For transplant episodes in which physician preference for inpatient transplant was the documented reason, this decision was made solely on the capacity of the patients' caregivers to perform outpatient care at home. More specifically, the decision to admit certain patients for transplant was taken if there was a history of a family being consistently unreliable with previous complex medical care prior to transplant. Other reasons for admission to the hospital for autoHSCT included monitoring for endocrine dysfunction and a decline in patient's overall health by the third transplant.

\section{Hospital resource utilization}

Utilization of hospital resources for all 90 transplant episodes is described in Table 3. Median days from transplant on admission for the outpatient cohort was day +6 (range +2 to 33 ) and day -4 (range -8 to 20) for the inpatient cohort $(p<0.001)$. From the time of stem cell infusion until engraftment, a total of $34(81 \%)$ outpatient transplant episodes required admission for febrile neutropenia, $3(7.1 \%)$ for other vital sign instabilities, and 5 (11.9\%) for other reasons. Other reasons included localized infection (cutaneous cellulitis and an infected urachus) and initiation of nasogastric tube feeds in the setting of significant weight loss and pain. The patients who were admitted to the hospital for other vital sign instabilities included those with hypotension and hypoxia without fever. Of the patients who received tandem transplants and had their initial autoHSCT in the outpatient setting, $19(68.5 \%)$ of patients did not require admission on subsequent cycles. For the patients who required tandem transplants and had their initial autoHSCT in the inpatient setting, 5 (27.8\%) of these patients had stem cell infusions performed in the outpatient setting on subsequent cycles.

Of all the patients admitted to the hospital, either for an inpatient transplant or upon admission following outpatient transplantation, nine and eight patients (18.4 vs $19.5 \%, p=$ 0.89 ) required ICU admission. Median time to ICU admission from autoHSCT was day +6 for the outpatient cohort and day +11 for the inpatient cohort $(p=0.75)$. The most common indication for ICU admission was vital sign abnormality for both the outpatient and inpatient cohorts (66.7 vs $50 \%, p=0.62$ ). Of the patients with vital sign abnormality, five patients in the outpatient cohort were admitted to the ICU for hypotension and one patient was admitted for persistent tachycardia in the setting of high fevers. Only one patient required 1 day of vasoactive medications to maintain adequate blood pressures. Within the outpatient cohort, two patients required transfer to the ICU for respiratory insufficiency/failure and one patient 
Table 3 Hospital-resource utilization between outpatient and inpatient transplant episodes

\begin{tabular}{|c|c|c|c|}
\hline & $\begin{array}{l}\text { Outpatient transplant } \\
\text { episodes }(n=49)\end{array}$ & $\begin{array}{l}\text { Inpatient transplant } \\
\text { episodes }(n=41)\end{array}$ & $p$ Value \\
\hline $\begin{array}{l}\text { Days from transplant on admission, } \\
\text { median (range) }\end{array}$ & $+6(+2$ to 33$)$ & $-4(-8$ to 20$)$ & $<0.001$ \\
\hline \multicolumn{4}{|l|}{$\begin{array}{l}\text { Primary reason for hospital admission } \\
\text { after outpatient autoHSCT, } n(\%)\end{array}$} \\
\hline Planned admission for HSCT & 0 & & \\
\hline Febrile neutropenia & $34(81.0)$ & & \\
\hline Vital sign instability (no fever) & $3(7.1)$ & & \\
\hline Others & $5(11.9)$ & & \\
\hline $\begin{array}{l}\text { Initial outpatient transplant followed } \\
\text { by inpatient transplant, } n(\%)\end{array}$ & $6(31.5)$ & - & \\
\hline $\begin{array}{l}\text { Initial inpatient transplant followed by } \\
\text { outpatient transplant, } n(\%)\end{array}$ & - & $5(27.8)$ & \\
\hline $\begin{array}{l}\text { Number of days in the hospital, } \\
\text { median (range) }\end{array}$ & $6(0-21)$ & $17(2-141)$ & $<0.001$ \\
\hline $\begin{array}{l}\text { Transplant episodes with ICU } \\
\text { admissions, } n(\%)\end{array}$ & $9(18.4)$ & $8(19.5)$ & 0.89 \\
\hline $\begin{array}{l}\text { Day post-autoHSCT when admitted to } \\
\text { ICU, median (range) }\end{array}$ & $+6(+3$ to 33$)$ & $+11(0-27)$ & 0.75 \\
\hline Length of ICU stay, median (range) & $0(0-4)$ & $0(0-37)$ & 0.13 \\
\hline Indication for ICU admission, $n(\%)$ & & & 0.62 \\
\hline Vital sign abnormality & $6(66.7)$ & $4(50)$ & \\
\hline Respiratory insufficiency/failure & $2(22.2)$ & $3(37.5)$ & \\
\hline Altered mental status & $1(11.1)$ & $1(12.5)$ & \\
\hline
\end{tabular}

HSCT hematopoietic stem cell transplantation
Fig. 1 Box and whisker plots for a comparing the number of hospital days between outpatient and inpatient transplant episodes and $\mathbf{b}$ comparing the number of days of antibiotic use between outpatient and inpatient transplant episodes. SEM indicates standard error of the mean

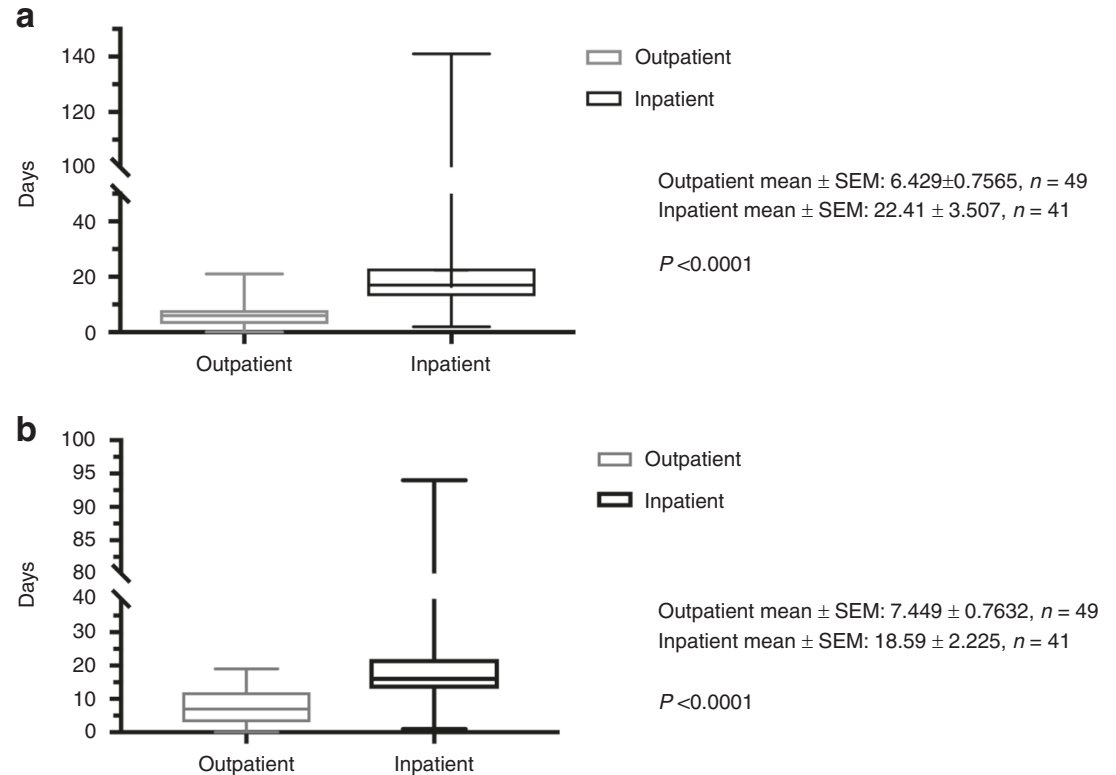

required 1 day of intubation. Within the inpatient cohort, four patients $(50 \%)$ required transfer to the ICU for vital sign abnormality. Of these patients, three patients had hypotension and one patient had persistent tachycardia in the setting of high fevers. One of these patients required vasoactive medications for a total of 3 days to maintain adequate blood pressures. Three patients required transfer to the ICU for respiratory insufficiency/failure and two required mechanical ventilation. For both the patients who were transferred to the ICU for an altered mental status, one was thought to be secondary to septic shock and the other required manipulation of their external ventricular drain. 

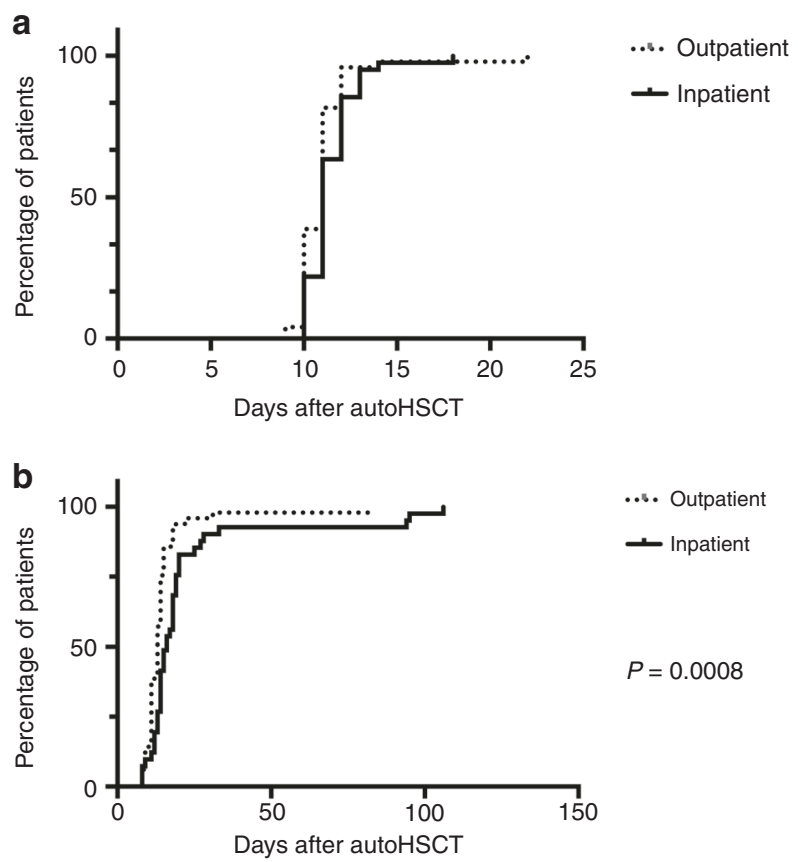

Fig. 2 Kaplan-Meier curve for a neutrophil engraftment of outpatient and inpatient transplant episodes, and for $\mathbf{b}$ platelet engraftment of outpatient and inpatient transplant episodes

The number of days spent in the hospital by the two cohorts is shown in Fig. 1a. The mean number of days spent in the hospital for the outpatient cohort was 6.4 days compared to 22.4 days for the inpatient cohort $(p<0.0001)$. The number of days of antibiotic use by the inpatient and outpatient cohorts is shown in Fig. 1b. The mean days of antibiotic use in the outpatient cohort was 7.4 days (range $0-19$ days) and 18.6 days (range 1-94 days) in the inpatient cohort $(p<0.0001)$.

\section{Engraftment}

Early-transplant outcomes and characteristics, including neutrophil and platelet engraftment, are shown in Fig. 2a, b. Engraftment was achieved in $100 \%$ of all transplant episodes. Neutrophil recovery occurred at the same time for both the cohorts, with a median time to neutrophil recovery of 11 days. The median time to platelet recovery occurred earlier in the outpatient cohort (13 days vs 16 days, $p=$ 0.0008).

\section{Infectious complications}

Infectious complications, antibiotics initiated, duration of antibiotic therapy, the number of blood cultures drawn, and days of infectious complications for both transplant episodes are shown in Table 4. A total of $26(53.1 \%)$ documented infections, including those from blood, stool, urine, and upper and lower respiratory tract, were isolated in the outpatient cohort, compared to 25 (67.6\%) infections in the inpatient cohort. A majority of these were bacterial infections $(80.8 \%$ outpatient vs $60 \%$ inpatient, $p=0.94)$. In the outpatient cohort, stool was the most common site of infection (46.2\%), with Clostridium difficile being the most commonly isolated organism. For the inpatient cohort, blood was the most common site of infection (40\%). Meropenem was the most common antibiotic initiated for both the cohorts (53.8\% outpatient vs $87.5 \%$ inpatient, $p=0.01$ ). For the outpatient cohort, the median time to isolate the infection was 6 days (range 2-28 days) compared to 7 days (range -5 to 120 days) for the inpatient cohort.

\section{Survival}

Figure 3 shows the OS for the entire cohort. At a median follow-up of 1.7 years (range 0.27-7.04 years) from the initial transplant for all patients, the OS was $66.1 \%$. At a follow-up time of day +100 , the transplant-related mortality (TRM) was $0 \%$ for both the cohorts. There were a total of 12 deaths. Eleven of these were from the progression of primary disease and one death was due to the complications related to radiation necrosis (Table 5).

\section{Discussion}

Our study of 37 patients shows the safety and efficacy of an outpatient transplant approach for autoHSCTs in medically stable pediatric CNS tumor patients. This is most clearly shown by the lack of TRM in both the outpatient and inpatient cohorts. Our results demonstrate that outpatientbased autoHSCT is feasible in selected cases and significantly reduces the length of hospital stay and antibiotic exposure, without an increase in complications.

This is the first analysis comparing the outcomes of pediatric CNS tumor patients undergoing autoHSCT in the outpatient and inpatient settings. There have been multiple reports in the adult literature describing a safe outpatientbased autoHSCT [29-33]. The experience with the outpatient management of autoHSCT in pediatric patients, more specifically CNS tumor patients, is not currently well described, and the data available are extrapolated from adult experience. The University of Montreal investigated the safety and efficacy of their outpatient program for autoHSCT in adult patients with multiple myeloma. All the 91 patients were treated on an identical outpatient protocol. Their results showed significant cost savings without a reduction in overall survival $(100 \%$ at day +100 from transplant) [34]. Limited data from the pediatric setting has also attempted to demonstrate the feasibility of stem cell transplant in the ambulatory setting. 
Table 4 Infectious complications of outpatient and inpatient transplant episodes

\begin{tabular}{|c|c|c|c|}
\hline & $\begin{array}{l}\text { Outpatient transplant } \\
\text { episodes }(n=49)\end{array}$ & $\begin{array}{l}\text { Inpatient transplant } \\
\text { episodes }(n=41)\end{array}$ & $p$ Value \\
\hline \multicolumn{4}{|l|}{ Antibiotics initiated, $n(\%)$} \\
\hline Meropenem & $21(53.8)$ & $35(87.5)$ & \multirow{5}{*}{0.01} \\
\hline Cefepime & $14(35.9)$ & $3(7.5)$ & \\
\hline Ceftazidime & $4(10.3)$ & $1(2.5)$ & \\
\hline Vancomycin & 0 & $1(2.5)$ & \\
\hline Clindamycin & 0 & 0 & \\
\hline $\begin{array}{l}\text { Total days of all antibiotics, } \\
\text { median (range) }\end{array}$ & $7(0-19)$ & $16(1-94)$ & $<0.0001$ \\
\hline \multicolumn{4}{|l|}{ Sets of blood cultures drawn } \\
\hline Mean \pm SD & $3.2 \pm 3.48$ & $5.15 \pm 9.09$ & 0.22 \\
\hline $\begin{array}{l}\text { Number of total documented } \\
\text { infections, } n(\%)\end{array}$ & $26(53.1)$ & $25(67.6)$ & 0.33 \\
\hline \multicolumn{4}{|l|}{ Sites of infection, $n(\%)$} \\
\hline CLABSI/blood & $5(19.2)$ & $10(40)$ & \multirow{6}{*}{0.86} \\
\hline Stool & $12(46.2)$ & $7(28)$ & \\
\hline Skin & $4(15.4)$ & $1(4)$ & \\
\hline Urine/urologic & $3(11.5)$ & 0 & \\
\hline Upper respiratory tract & $2(7.7 \%)$ & $5(20)$ & \\
\hline Lungs & 0 & $2(8)$ & \\
\hline \multicolumn{4}{|l|}{ Type of infection, $n(\%)$} \\
\hline Bacterial & $21(80.8)$ & $15(60)$ & \multirow{3}{*}{0.09} \\
\hline Viral & $5(19.2)$ & $9(36)$ & \\
\hline Fungal & 0 & $1(4)$ & \\
\hline $\begin{array}{l}\text { Days from transplant infection } \\
\text { identified, median (range) }\end{array}$ & $6(2-28)$ & $7(-5-120)$ & 0.08 \\
\hline
\end{tabular}

$S D$ standard deviation, CLABSI central line-associated bloodstream infection

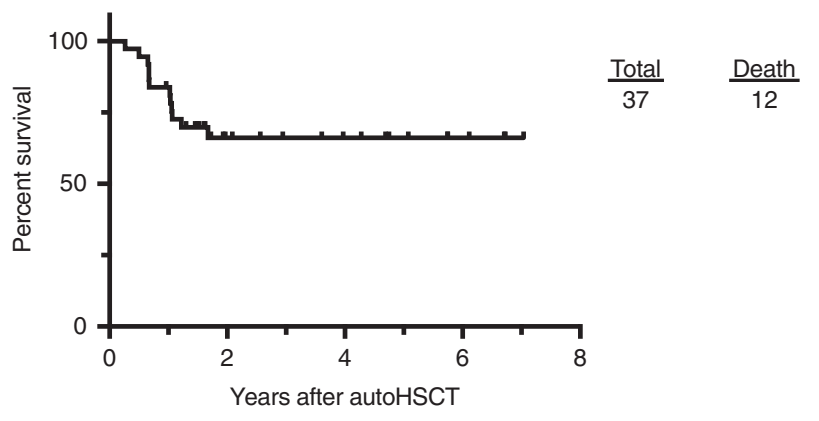

Fig. 3 Kaplan-Meier curve for the overall survival of all the 37 patients

Previously, concerns for the safety of outpatient management of pediatric patients following high-dose conditioning regimens were included, but were not limited to mucositis, infections, and organ dysfunction, leading to the presumption that patients require a close monitoring within the hospital. Despite outpatient management, we observed a reduction in the number of serious infections. This is especially important as these patients did not receive an
Table 5 Cause of death

\begin{tabular}{lc}
\hline Cause & $n(\%)$ \\
\hline Progressive disease, $n(\%)$ & $11(91.7)$ \\
Radiation necrosis, $n(\%)$ & $1(8.3)$
\end{tabular}

Data presented are $n(\%)$ unless otherwise indicated

empiric antibiotic prophylaxis to prevent serious bacterial infections. We saw a reduced number of CLABSI in the outpatient cohort compared to that in the inpatient cohort. Possible considerations as to why this may have been observed in the outpatient cohort include decreased centralline manipulation, less-intensive monitoring of fever, perhaps leading to less-frequent initiation of antibiotics, and fewer virulent microorganisms that exist outside the hospital. The majority of outpatient transplant episodes (34/49, $81 \%$ ) ultimately required readmission to the hospital for febrile neutropenia; however, none of these episodes resulted in death from infection. The discrepancy in the number of days of antibiotic use and the length of 
hospitalization stays between the outpatient and inpatient cohorts is largely explained by the initiation of antibiotics for any incidence of fever or ANC that dropped below 500/ $\mathrm{mm}^{3}$ for all patients with transplants performed in the inpatient setting per our institutional guidelines. Additionally, the difference in the lengths of hospitalization stay between the outpatient and inpatient cohorts may also be explained by our institution's practice of meeting the strict criteria of attaining an ANC $>2500 / \mathrm{mm}^{3}$ for 3 consecutive days before discontinuation of G-CSF in the inpatient setting. Also, the advantage of admitting patients within the outpatient cohort at the time of febrile neutropenia may have contributed to the decreased number of antibiotic days and hospitalization days.

The outpatient cohort also achieved a significantly faster platelet engraftment compared to the inpatient cohort. This difference may have been secondary to the prolonged use of G-CSF in the inpatient setting, which may have driven the development of hematopoietic precursor cells along the granulocyte pathway, potentially delaying the maturation of platelet progenitor cells. An additional reason may be that patients in the outpatient cohort were healthier at baseline and less heavily pre-treated prior to the time of transplant.

The lack of TRM and the low incidence of serious complications related to infection are likely due to the stringent compliance with our outpatient supportive-care practice. This is best demonstrated by the lower incidence of CLABSI in the outpatient cohort of all documented infections. However, the lack of TRM in the outpatient cohort also may reflect higher KPS/LPS scores and fewer co-morbidities, reflecting a healthier baseline status and a lessheavy treatment prior to transplant. Potential weaknesses of our study include the retrospective nature of this study, although patients were equally distributed based on age, diagnosis, and preparative regimen. Given the retrospective nature, patients were not randomized to have transplants in the outpatient or inpatient setting and were rather assessed by the treating physician, in conjunction with the family for the adequacy of outpatient transplant. It is possible that neither group identified the subtle characteristics not captured here, which led to the in- or outpatient treatment. Additionally, allowing parental preference to play a role in how transplants were performed (outpatient vs inpatient setting) adds a selection bias, favoring highly motivated caregivers wanting to limit the time within the hospital to receive outpatient therapy. Because our outpatient autoHSCT patients were carefully selected and monitored according to well-established and strict institutional outpatient-care guidelines, these results are not necessarily generalizable to all pediatric neuro-oncology patients.

This study demonstrates that outpatient autoHSCT is safe and efficacious for children with brain tumors. Such an approach can be applied to a vast majority of pediatric CNS tumor patients and has clinical outcomes comparable to those patients managed in the traditional inpatient setting. These data that we have presented here, however, are largely applicable to patients who have received carboplatin and thiotepa as a part of their conditioning regimen, which was used in a majority of our patients. Other myeloablative regimens may need a more intensive support that is not feasible in the outpatient setting. While beyond the scope of this analysis, it is clear that this approach has the potential to drive a significant reduction in the utilization of hospitalization resources.

Acknowledgements The authors would like to acknowledge the neuro-oncology and bone marrow transplant staff for their excellent patient care.

\section{Compliance with ethical standards}

Conflict of interest The authors declare that they have no conflict of interest.

Publisher's note: Springer Nature remains neutral with regard to jurisdictional claims in published maps and institutional affiliations.

Open Access This article is licensed under a Creative Commons Attribution 4.0 International License, which permits use, sharing, adaptation, distribution and reproduction in any medium or format, as long as you give appropriate credit to the original author(s) and the source, provide a link to the Creative Commons license, and indicate if changes were made. The images or other third party material in this article are included in the article's Creative Commons license, unless indicated otherwise in a credit line to the material. If material is not included in the article's Creative Commons license and your intended use is not permitted by statutory regulation or exceeds the permitted use, you will need to obtain permission directly from the copyright holder. To view a copy of this license, visit http://creativecommons. org/licenses/by/4.0/.

\section{References}

1. Fangusaro J, Finlay J, Sposto R, Ji L, Saly M, Zacharoulis S, et al. Intensive chemotherapy followed by consolidative myeloablative chemotherapy with autologous hematopoietic cell rescue (AuHCR) in young children with newly diagnosed supratentorial primitive neuroectodermal tumors (sPNETs): report of the Head Start I and II experience. Pediatr Blood Cancer. 2008; 50:312-8.

2. Bergthold G, El Kababri M, Varlet P, Dhermain F, Sainte-Rose C, Raquin MA, et al. High-dose busulfan-thiotepa with autologous stem cell transplantation followed by posterior fossa irradiation in young children with classical or incompletely resected medulloblastoma. Pediatr Blood Cancer. 2014;61:907-12.

3. Broniscer A, Nicolaides TP, Dunkel IJ, Gardner SL, Johnson J Jr., Allen JC, et al. High-dose chemotherapy with autologous stemcell rescue in the treatment of patients with recurrent noncerebellar primitive neuroectodermal tumors. Pediatr Blood Cancer. 2004;42:261-7.

4. Cheuk DK, Lee TL, Chiang AK, Ha SY, Chan GC. Autologous hematopoietic stem cell transplantation for high-risk brain tumors in children. J Neurooncol. 2008;86:337-47. 
5. Dunkel IJ, Boyett JM, Yates A, Rosenblum M, Garvin JH Jr., Bostrom BC, et al. High-dose carboplatin, thiotepa, and etoposide with autologous stem-cell rescue for patients with recurrent medulloblastoma. Children's Cancer Group. J Clin Oncol. 1998;16:222-8.

6. Fangusaro JR, Jubran RF, Allen J, Gardner S, Dunkel IJ, Rosenblum M, et al. Brainstem primitive neuroectodermal tumors (bstPNET): results of treatment with intensive induction chemotherapy followed by consolidative chemotherapy with autologous hematopoietic cell rescue. Pediatr Blood Cancer. 2008;50:715-7.

7. Finlay JL. The role of high-dose chemotherapy and stem cell rescue in the treatment of malignant brain tumors. Bone Marrow Transplant. 1996;18(Suppl 3):S1-5.

8. Gardner SL, Asgharzadeh S, Green A, Horn B, McCowage G, Finlay J. Intensive induction chemotherapy followed by high dose chemotherapy with autologous hematopoietic progenitor cell rescue in young children newly diagnosed with central nervous system atypical teratoid rhabdoid tumors. Pediatr Blood Cancer. 2008;51:235-40.

9. Graham ML, Herndon JE 2nd, Casey JR, Chaffee S, Ciocci GH, Krischer JP, et al. High-dose chemotherapy with autologous stemcell rescue in patients with recurrent and high-risk pediatric brain tumors. J Clin Oncol. 1997;15:1814-23.

10. Perez-Martinez A, Quintero V, Vicent MG, Sevilla J, Diaz MA, Madero L. High-dose chemotherapy with autologous stem cell rescue as first line of treatment in young children with medulloblastoma and supratentorial primitive neuroectodermal tumors. J Neurooncol. 2004;67:101-6.

11. Shih CS, Hale GA, Gronewold L, Tong X, Laningham FH, Gilger EA, et al. High-dose chemotherapy with autologous stem cell rescue for children with recurrent malignant brain tumors. Cancer . 2008;112:1345-53.

12. Sung KW, Lim DH, Yi ES, Choi YB, Lee JW, Yoo KH, et al. Tandem high-dose chemotherapy and autologous stem cell transplantation for atypical teratoid/rhabdoid tumor. Cancer Res Treat. 2016;48:1408-19.

13. Sung KW, Yoo KH, Cho EJ, Koo HH, Lim DH, Shin HJ, et al. High-dose chemotherapy and autologous stem cell rescue in children with newly diagnosed high-risk or relapsed medulloblastoma or supratentorial primitive neuroectodermal tumor. Pediatr Blood Cancer. 2007;48:408-15.

14. Castagnola E, Faraci M, Moroni C, Bandettini R, Caruso S, Bagnasco $\mathrm{F}$, et al. Bacteremias in children receiving hemopoietic SCT. Bone Marrow Transplant. 2008;41(Suppl 2):S104-6.

15. Mullen CA, Nair J, Sandesh S, Chan KW. Fever and neutropenia in pediatric hematopoietic stem cell transplant patients. Bone Marrow Transplant. 2000;25:59-65.

16. Choi YB, Yi ES, Kang JM, Lee JW, Yoo KH, Kim YJ, et al. Infectious complications during tandem high-dose chemotherapy and autologous stem cell transplantation for children with highrisk or recurrent solid tumors. PLoS One. 2016;11:e0162178.

17. Srinivasan A, McLaughlin L, Wang C, Srivastava DK, Shook DR, Leung W, et al. Early infections after autologous hematopoietic stem cell transplantation in children and adolescents: the St. Jude experience. Transpl Infect Dis. 2014;16:90-7.

18. Choeyprasert W, Hongeng S, Anurathapan U, Pakakasama S. Bacteremia during neutropenic episodes in children undergoing hematopoietic stem cell transplantation with ciprofloxacin and penicillin prophylaxis. Int J Hematol. 2017;105:213-20.

19. Brown RH, Subramanian A, Hwang CS, Chang S, Awad SS. Comparison of infectious complications with synthetic mesh in ventral hernia repair. Am J Surg. 2013;205:182-7.
20. Abid MB, Christopher D, Abid MA, Poon ML, Tan LK, Koh LP, et al. Safety and cost-effectiveness of outpatient autologous transplantation for multiple myeloma in Asia: single-center perspective from Singapore. Bone Marrow Transplant. 2017;52:1044-6.

21. Graff TM, Singavi AK, Schmidt W, Eastwood D, Drobyski WR, Horowitz M, et al. Safety of outpatient autologous hematopoietic cell transplantation for multiple myeloma and lymphoma. Bone Marrow Transplant. 2015;50:947-53.

22. Martino M, Lemoli RM, Girmenia C, Castagna L, Bruno B, Cavallo $\mathrm{F}$, et al. Italian consensus conference for the outpatient autologous stem cell transplantation management in multiple myeloma. Bone Marrow Transplant. 2016;51:1032-40.

23. Solomon SR, Matthews RH, Barreras AM, Bashey A, Manion KL, McNatt K, et al. Outpatient myeloablative allo-SCT: a comprehensive approach yields decreased hospital utilization and low TRM. Bone Marrow Transplant. 2010;45:468-75.

24. Gertz MA, Buadi FK, Hayman SR, Lacy MQ, Dispenzieri A, Dingli D, et al. Safety outcomes for autologous stem cell transplant in multiple myeloma. Mayo Clin Proc. 2018;93:56-8.

25. Martino M, Ciavarella S, De Summa S, Russo L, Meliambro N, Imbalzano L, et al. A comparative assessment of quality of life in patients with multiple myeloma undergoing autologous stem cell transplantation through an outpatient and inpatient model. Biol Blood Marrow Transplant. 2018;24:608-13.

26. Martino M, Console G, Russo L, Meliado A, Meliambro N, Moscato T, et al. Autologous stem cell transplantation in patients with multiple myeloma: an activity-based costing analysis, comparing a total inpatient model versus an early discharge model. Clin Lymphoma Myeloma Leuk. 2017;17:506-12.

27. Cohen BH, Geyer JR, Miller DC, Curran JG, Zhou T, Holmes E, et al. Pilot study of intensive chemotherapy with peripheral hematopoietic cell support for children less than 3 years of age with malignant brain tumors, the CCG-99703 Phase I/II Study. A report from the Children's Oncology Group. Pediatr Neurol. 2015;53:31-46.

28. Horan TC, Andrus M, Dudeck MA. CDC/NHSN surveillance definition of health care-associated infection and criteria for specific types of infections in the acute care setting. Am J Infect Control. 2008;36:309-32.

29. Rovira M. Outpatient management of autologous haematopoietic cell transplantation: the Barcelona experience. Presse Med. 2004;33:479-81.

30. Peters WP, Ross M, Vredenburgh JJ, Hussein A, Rubin P, Dukelow K, et al. The use of intensive clinic support to permit outpatient autologous bone marrow transplantation for breast cancer. Semin Oncol. 1994;21(4 Suppl 7):25-31.

31. Leger C, Sabloff M, McDiarmid S, Bence-Bruckler I, Atkins H, Bredeson $\mathrm{C}$, et al. Outpatient autologous hematopoietic stem cell transplantation for patients with relapsed follicular lymphoma. Ann Hematol. 2006;85:723-9.

32. Fernandez-Aviles F, Carreras E, Urbano-Ispizua A, Rovira M, Martinez C, Gaya A, et al. Case-control comparison of at-home to total hospital care for autologous stem-cell transplantation for hematologic malignancies. J Clin Oncol. 2006;24:4855-61.

33. Chandrasekar PH, Abraham OC, Klein J, Alangaden G, Chalasani $\mathrm{G}$, Cassells L, et al. Low infectious morbidity after intensive chemotherapy and autologous peripheral blood progenitor cell transplantation in the outpatient setting for women with breast cancer. Clin Infect Dis. 2001;32:546-51.

34. Holbro A, Ahmad I, Cohen S, Roy J, Lachance S, Chagnon M, et al. Safety and cost-effectiveness of outpatient autologous stem cell transplantation in patients with multiple myeloma. Biol Blood Marrow Transplant. 2013;19:547-51. 